\title{
Metodologias ativas e docência no Ensino Superior: um cenário que demanda por competência pedagógica
}

\author{
Active methodologies and teaching in Higher Education: \\ a scenario that requires a pedagogical skill
}

Méthodologies actives et enseignement dans L'enseignement Supérieur: un scénario qui demande une compétence pédagogique

João Wilson Savino Carvalho ${ }^{1}$

Universidade Federal do Amapá

Silvana Malusáa
Universidade Federal de Uberlândia

Alexandre Leite dos Santos Silva ${ }^{3}$

Universidade Federal do Piauí

\begin{abstract}
Alexandre Fonseca Santos ${ }^{4}$
Fundação Uberlandense de Turismo Esporte e Lazer

Liliane Rodrigues Vás ${ }^{5}$

Secretaria de Estado de Minas Gerais

Fausto Reis Nogueira ${ }^{6}$ Secretaria de Estado de Minas Gerais
\end{abstract}

Resumo: Esse artigo tem como objetivo mostrar a importância das metodologias ativas no Ensino Superior e a necessidade, para a sua implantação, de competências pedagógicas do professor universitário. A pesquisa baseou-se na revisão da literatura científica e na aplicação de um questionário a 25 docentes, da área da saúde, de uma universidade mineira. Concluiu que as metodologias ativas estão em consonância com a formação crítica e reflexiva esperada pela educação superior, além de enriquecerem o espaço da sala de aula. Ademais, chegou-se à conclusão que o professor universitário necessita de um espaço permanente e dialógico para

\footnotetext{
1 Doutor em Educação. Professor Associado da Universidade Federal do Amapá (Unifap). Graduado em Filosofia, Psicologia e Direito. Especialista em Educação de Adultos (UFPB/PPGED/UFU). E-mail: wilsoncarvalho@unifap.br

${ }^{2}$ Professora Associada IV da Universidade Federal de Uberlândia (UFU). Doutora e Pós-doutora em Educação. Coordenadora Pedagógica DINTER/UFU/UFPI. Coordenadora do Grupo de Pesquisa Desenvolvimento profissional e docência universitária: saberes e práticas educativas. E-mail: silmalusa@yahoo.com.br

${ }^{3}$ Professor Efetivo na Universidade Federal do Piauí (UFPI), Campus Picos. Doutor e Mestre em Educação. Email: alexandre.leite@ufu.br.

${ }^{4}$ Mestre em Educação Universidade Federal de Uberlândia (UFU). Formação Inicial: Educação Física - Curso de Graduação Universidade Federal de Uberlândia. Professor de Educação Física na Escola Estadual (pública) em Uberlândia e como profissional de Educação Física na Fundação Uberlandense de Turismo Esporte e Lazer (FUTEL).E-mail: alexandrefonsecasantos@hotmail.com

${ }_{5}^{5}$ Mestranda em Educação pela Universidade Federal de Uberlândia. Especialista em Inspeção e Supervisão Escolar. Assessora Educacional da Prefeitura de Monte Carmelo-MG. Atua na Secretaria de Estado de Minas Gerais (SEEMG).E-mail: lilianervaz@yahoo.com.br

${ }^{6}$ Formado em Direito e Pedagogia pela Universidade Federal de Uberlândia (UFU). Secretaria de Estado de Minas Gerais (SEEMG). E-mail: fausto.reis@educacao.mg.gov.br
} 
a construção da competência pedagógica que favoreça a introdução e o uso eficaz das metodologias ativas.

Palavras-chave: Metodologias ativas. Ensino superior. Docência universitária.

Abstract: This article aims to show the importance of active methodologies in Higher Education and the need, for its implementation, of pedagogical skills of the university professor. The research was based on the review of the scientific literature and the application of a questionnaire to 25 teachers from the health area of a university in Minas Gerais. It concluded that the active methodologies are in line with the critical and reflexive formation expected by higher education, besides enriching the space of the classroom. In addition, it was concluded that the university professor needs a permanent and dialogical space for the construction of pedagogical competence that favors the introduction and effective use of active methodologies.

Keywords: Active methodologies. Higher education. University teaching

Résumé: Cet article vise à montrer l'importance des méthodologies actives dans l'enseignement supérieur et la nécessité, pour sa mise en ouvre, des compétences pédagogiques du professeur d'université. La recherche était basée sur l'examen de la littérature scientifique et l'application d'un questionnaire à 25 enseignants du secteur de la santé d'une université de Minas Gerais. Il a conclu que les méthodologies actives correspondaient à la formation critique et réflexive attendue par l'enseignement supérieur, en plus d'enrichir l'espace de la salle de classe. En outre, il a été conclu que le professeur d'université avait besoin d'un espace permanent et dialogique pour la construction de compétences pédagogiques favorisant l'introduction et l'utilisation efficace de méthodologies actives.

Mots clés: Méthodologies actives. L'enseignement supérieur. Enseignement universitaire

Recebido em: 15 de setembro de 2018 Aceito em: 18 de dezembro de 2018

\section{Introdução}

Vivenciamos um processo de mudança de cultura no cenário universitário: antes voltada para o ensino e agora voltada para a aprendizagem, conforme Zabalza (2004). Nesse sentido, são inseridas, dentro desse cenário, as metodologias ativas, que colocam o aluno universitário como verdadeiro protagonista no processo de ensino-aprendizagem. No entanto, essa mudança de cultura exige dos docentes no Ensino Superior um novo tipo de atuação, com o qual não estão habituados e no qual devem assumir o seu papel pedagógico.

Diante desse novo cenário universitário, este artigo busca discutir sobre as seguintes questões: O que são as metodologias ativas e qual a sua importância no Ensino Superior? O que é necessário para que o docente universitário tenha condições de desenvolvê-las na sua 
prática? Dentro dessa problemática, apresentamos os resultados de uma pesquisa com 25 professores universitários, de cursos da área da saúde.

\section{Metodologias ativas: sua importância para um ensino de qualidade}

\subsection{O que são metodologias ativas?}

Entendemos que uma cultura universitária voltada para a aprendizagem é aquela que foca no aluno em vez de no professor, através de atividades que os estimulem para a aprendizagem e que os tornem responsáveis por ela. O professor, nesse cenário, deixa de ser um mero transmissor, próprio da educação bancária, isto é, a quem cabe "dar, entregar, levar, transmitir", para atuar como "orientador, supervisor, facilitador do processo de aprendizagem” (FREIRE, 2013, p. 83; BARBOSA; MOURA, 2013). Essa visão do novo papel do professor e do aluno é que direciona a implantação e o desenvolvimento das metodologias ativas.

Conforme Barbosa e Moura (2013, p. 55) as metodologias ativas são "atividades que ocupam o aluno em fazer alguma coisa e, ao mesmo tempo, o levam a pensar sobre as coisas que está fazendo”. Nesse sentido, envolvem estratégias que visam promover a aprendizagem ativa, que, por sua vez, se consiste em "um processo, um método e uma filosofia de educação na qual o estudante adquire conhecimento por meio de seus próprios esforços e desenvolve a capacidade de questionar e de avaliar criticamente" (MOTA; SCOTT, 2014, p. 81). Assim, podemos definir as metodologias ativas como aquelas metodologias que colocam o aluno como responsável pela sua própria aprendizagem, levando-o a ter autonomia para se conhecer e explorar as suas capacidades para adquirir conhecimentos, habilidades e atitudes.

Entretanto, essa autonomia e esse construir a própria aprendizagem não exclui, evidentemente, o papel do outro, como o professor e os colegas, no processo de aprendizagem, pois entendemos que a realidade é construída socialmente (BERGER; LUCKMANN, 2004). No entanto, apesar do conhecimento ser uma construção social é também uma construção individual, que não pode ser forçado, empurrado para dentro, mas é construído, num processo dotado de sentido e idiossincrático, a partir da receptividade e da voluntariedade do aprendiz (REY, 1997). Assim, as metodologias ativas conjuntam dialeticamente o individual com o social, o independente com o interdependente, o interno e o externo, o singular com o plural, o único com o coletivo, mas sempre prezando a assunção da atividade do e pelo aluno. 
Alguns exemplos, encontrados na literatura, de metodologias ativas são: a instrução aos pares (peerinstruction); o ensino sob medida (just-in-time-teaching); a aprendizagem baseada em problemas; e a aprendizagem baseada em projetos, dentre outros (MAZUR, 2015; BARBOSA; MOURA, 2013; MOTA; SCOTT, 2014).

A instrução aos pares é um método desenvolvido por Eric Mazur, professor da Universidade de Harvard, no qual a socialização entre colegas de suas pesquisas individuais, resultados alcançados e argumentos produzidos, assume um papel importante na aprendizagem. Geralmente, a instrução aos pares é conjugada com o ensino sob medida, que requer do professor que adapte a sua aula às necessidades da turma, com base em testes de diagnóstico breves e na preparação antecipada e extraclasse dos alunos (MAZUR, 2015).

A aprendizagem baseada em problemas é um método em que o professor usa uma situação-problema como dinamizadora da aprendizagem autodirigida dos seus alunos. Será uma aprendizagem autodirigida porque o professor trabalhará apenas como facilitador e orientador durante a resolução do problema, que poderá incluir etapas, com realizações individuais e/ou em grupo, indo desde a compreensão do problema e a pesquisa, ou a decomposição em problemas menores, até à síntese, discussão, avaliação e apresentação dos resultados (BARBOSA; MOURA, 2013).

A aprendizagem baseada em projetos, por sua vez, envolve, geralmente por um grupo de alunos, a construção de algo ou a pesquisa em torno de um problema ou situação, contextualizada. Envolve uma finalidade, com objetivos e cronograma bem definidos, e recursos disponíveis. Implica na socialização do trabalho e dos resultados. Mais uma vez, o professor não ficará controlando o passo-a-passo do processo, mas atuará como um orientador, talvez até ajudando a levantar mais questões em torno do projeto (BARBOSA; MOURA, 2013).

Em cada uma dessas metodologias, seja no intercâmbio de ideias entre colegas, ou no desenvolvimento de atividades antes da aula pelos alunos, ou no trabalho colaborativo em projetos ou na investigação para a solução de problemas, vemos alunos atuando de forma autônoma em prol de sua própria aprendizagem. Mas isso por si só não torna a aprendizagem ativa importante no Ensino Superior, pois existem outros motivos.

\subsection{A importância das metodologias ativas no Ensino Superior}

Uma das finalidades da educação superior, segundo a Lei de Diretrizes e Bases da Educação Nacional, no artigo 43, inciso I, é “estimular a criação cultural e o desenvolvimento 
do espírito científico e do pensamento reflexivo" (BRASIL, 1996). Compreende-se, pela legislação supracitada, que as instituições de Ensino Superior têm o dever de atuar para a promoção do desenvolvimento humano e dos níveis mais complexos do pensamento. Esse objetivo só pode ser alcançado ao colocarmos o aluno como protagonista da sua própria aprendizagem, como responsável por ela, e com capacidade de não apenas adquirir, de forma autônoma e coletiva, novos conhecimentos, atitudes e habilidades, mas de adquiri-los com senso crítico e com uma postura reflexiva, características fundamentais do espírito científico. Nessa ótica é que as metodologias ativas encenam como importantes coadjuvantes no processo de ensino-aprendizagem, como enzimas catalizadoras das atividades discentes.

As metodologias ativas devem despertar a curiosidade à medida que os alunos adquirem conhecimento teórico e incorporam elementos novos, não apontados ainda nas aulas. Nesse sentido, os alunos, quando têm autonomia para contribuir com as aulas, sentemse mais valorizados, estimulados e engajados nos estudos. Segundo Paulo Freire (2003), o que impulsiona a aprendizagem é a superação de desafios, a resolução de problemas e a construção do conhecimento novo a partir de conhecimentos e experiências prévias do indivíduo.

Vale ainda mencionar o texto de Gemignani (2012), que conceitua as metodologias ativas como sendo uma concepção educativa que estimula os processos construtivos de açãoreflexão-ação. Seguindo os preceitos formulados por Paulo Freire, propõe uma educação pautada na liberdade, na autonomia e postura ativa por parte do aluno, em relação ao seu aprendizado.A autora aponta que as metodologias são um dos caminhos possíveis para se aprender pensar, de modo criativo e adequado às necessidades da sociedade - uma metodologia norteada, dentre outros meios, pela problematização, desafios e a descoberta de possíveis soluções de problemas. Segunda ela, a metodologia ativa é um processo educativo que se fundamenta na relação professor-aluno, tomando estes como sujeitos construtores do processo educativo, em contínua e permanente interação.

Ademais, o desenvolvimento do espírito crítico e reflexivo, proporcionado pelas metodologias ativas coloca o aluno num nível mais elevado de aprendizagem, segundo a taxionomia revisada de Bloom (ANDERSON et al., 2001), o qual é um dos objetivos da universidade. Conforme essa taxionomia, a aprendizagem acontece em níveis de cognição que podem ser mais ou menos complexos. O nível de complexidade aumenta, de modo crescente, na seguinte ordem: memorização, compreensão, aplicação, análise, avaliação e criação (ANDERSON et al., 2001). Os métodos ativos estimulam níveis mais elevados de aprendizagem, como a aplicação e a criação, ao contrário dos métodos tradicionais de ensino, 
baseados na memorização de dados e, no máximo, na compreensão de conceitos, níveis menos complexos de aprendizagem. Desse modo, as metodologias ativas são importantes para um processo de ensino-aprendizagem com qualidade no Ensino Superior.

\section{Metodologias ativas e a competência pedagógica do docente universitário}

\subsection{Metodologias ativas e competência pedagógica: um diálogo necessário}

Dentro desse novo cenário, configurado pelo aluno protagonista e pelo papel das metodologias ativas, entra o professor universitário, um profissional, que apesar da alta especialização conteudista, carece do instrumental e do teórico pedagógicos na sua prática (MASETTO, 2012). Essa situação do professor universitário parece contraditória, pois ao adotar as metodologias ativas, que ressaltam a responsabilidade e autonomia do aluno no seu processo de aprendizagem, é requerido mais desse profissional no que tange à sua competência pedagógica. Desse modo, tornar-se o aluno ativo quanto à sua própria aprendizagem não quer dizer que o professor deixará de ter um papel ativo no ensino, pois aprendizagem e ensino se complementam. Assim, cabe ao professor não apenas reconhecer os benefícios das metodologias ativas para a aquisição de conhecimentos e formação dos alunos, mas refletir e preparar-se pedagogicamente de modo criar condições para a sua implementação, ou seja, é necessário que o professor universitário desenvolva competências pedagógicas.

Entendemos que competência pedagógica, envolve, segundo Masetto (2003b, p. 2023), quatro aspectos:

a) O entendimento do significado do processo de ensino-aprendizagem. A aprendizagem dos alunos é o foco principal da docência. Cabe ao professor compreender os princípios básicos da aprendizagem, as teorias educacionais e seus pressupostos, pautados em aspectos cognitivos, afetivos, que contribua para o desenvolvimento pleno das potencialidades discentes;

b) O comprometimento com a concepção e gestão do currículo. O professor deve "circular" por todos os campos e áreas do conhecimento. Não deve estar "preso" ou limitado apenas à disciplina a qual leciona ou a um campo específico do saber. O professor deve estar 
atento às nuances do currículo e ter conhecimento claro e sucinto sobre as relações e inter-relações que envolvem a sua construção;

c) A compreensão do papel das relações sociais em sala de aula. A universidade não deve priorizar tão somente a formação de futuros profissionais para atuarem no mercado de trabalho. A sala de aula é um espaço sociocultural e político. A formação universitária deve estar diretamente voltada para a constituição de sujeitos críticos e reflexivos perante a sociedade;

d) O domínio da tecnologia educacional. O professor não pode ignorar que o uso da tecnologia, associado a uma metodologia de ensino eficaz, que pode auxiliar no processo de ensino e aprendizagem em sala de aula. Cabe ao professor o domínio prático e teórico da tecnologia educacional. O uso de computador, da internet e de diferentes estratégias constitui possibilidade real para a melhoria do ensino.

Assim, podemos dizer que esses são aspectos fundamentais da competência pedagógica do professor universitário.

Tais aspectos, que compõem a competência pedagógica do professor universitário, são necessários para a implementação, na prática docente, das metodologias ativas. É fácil exemplificar isso: Como poderá o professor valorizar a importância das metodologias ativas sem compreender os processos pelos quais se dá a aprendizagem? Como poderá o professor adaptar o seu planejamento e a execução das suas aulas se não assumir e entender o seu papel como gestor do currículo? Poderá o professor aplicar a instrução aos pares, um tipo de metodologia ativa, se não compreender o papel das relações "professor-aluno" e "alunoaluno", com diria Maseto (2003b, p.22), no processo de ensino-aprendizagem? Além disso, as metodologias ativas se constituem em novas tecnologias educacionais, cujo sucesso e continuidade dependem do domínio que o professor universitário tenha delas.

\subsection{Necessidades formativas do docente universitário}

Em suma, sabendo do que se requer do docente universitário, em termos de competência pedagógica, para a adoção das metodologias ativas, somos levados a refletir sobre o tipo de necessidades formativas desse profissional. Nesse sentido, fazemos alusão ao trabalho desenvolvido por Malusá (2003), no contex to de um Programa de Atualização para docentes universitários, com uma IES da região do Triângulo Mineiro. O seu trabalho de 
pesquisa chegou à seguinte conclusão sobre como prover formação continuada aos docentes universitários: "criar um espaço coletivo e permanente para discussão sobre docência universitária” (MALUSÁ, 2003, p. 164).

Concordemente, entendemos que um espaço institucional permanente de formação, que envolva uma participação coletiva e dialógica, poderá ser um caminho eficaz para a construção da competência pedagógica, cujo termo "competência”, que envolve capacidade, perpassa a teoria, para a prática docente. Naturalmente, esse espaço formativo e institucional deverá dar atenção não apenas às necessidades formativas pedagógicas do docente universitário, mas também suas necessidades formativas no que toca às dimensões pessoal e profissional do seu trabalho, conforme Zabalza (2003).

\section{Pesquisa com professores universitários da área da saúde}

Com o propósito de investigar como os professores universitários percebem as formas de ensino participativas, que valorizam a aprendizagem ativa, e a importância da preparação pedagógica do professor, realizamos uma pesquisa por meio de um questionário com 25 professores de cursos da área da saúde de uma universidade mineira, conforme apresenta o gráfico 1 , a seguir.

\section{Gráfico 1 - Quantidade de professores participantes da pesquisa dos corpos docentes} dos cursos

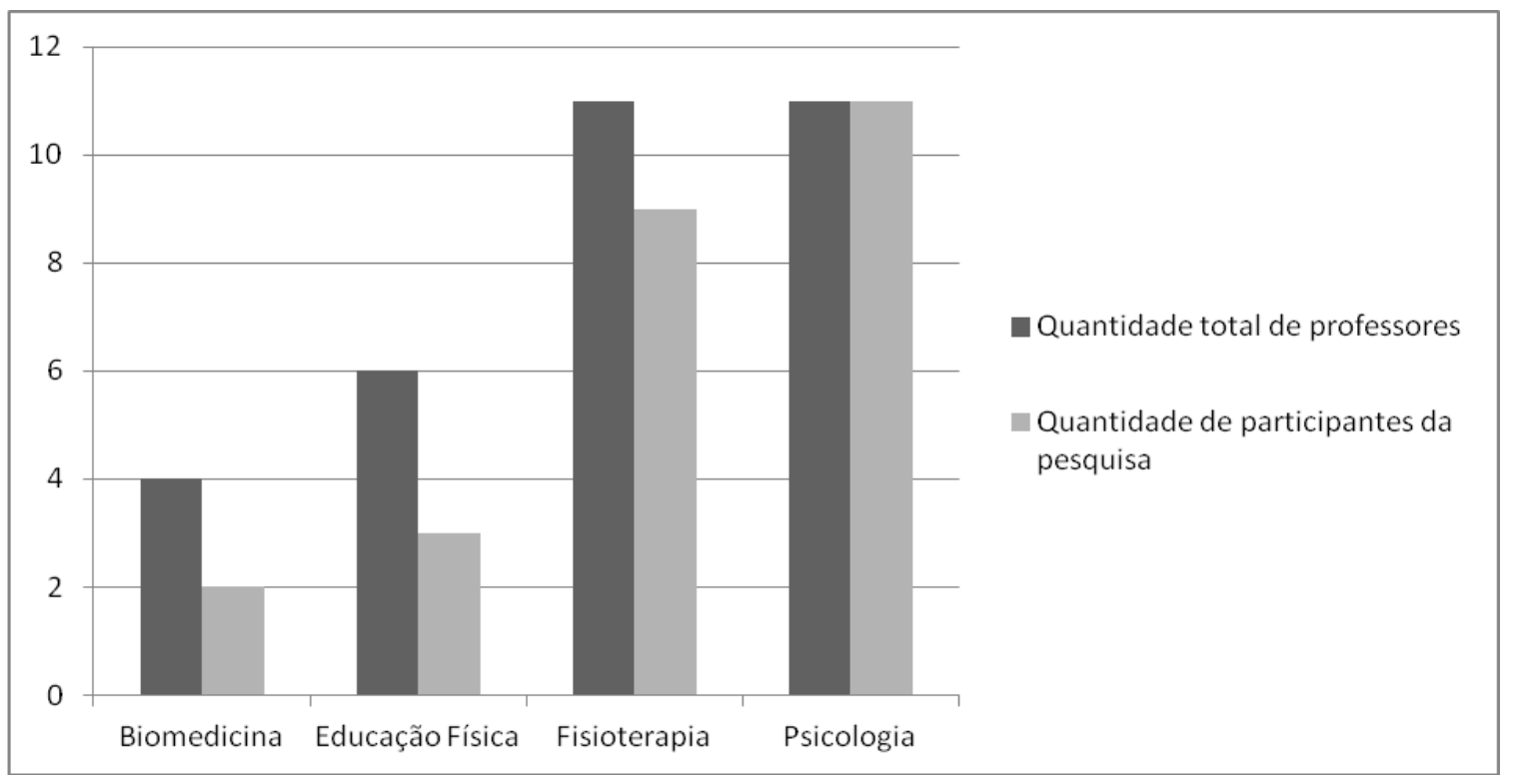

Fonte: Os autores 
Como mostra o gráfico 1, do total de professores participantes, 2 (8\%) eram professores do curso de Biomedicina, 3 (12\%) eram professores do curso de Educação Física, 9 (36\%) eram professores do curso de Fisioterapia e 11 (44\%) eram professores do curso de Psicologia. A quantidade de professores universitários foi significativa, com uma amostra representativa, pois todos os professores do curso de Psicologia participaram da pesquisa, além de $82 \%$ dos docentes do curso de fisioterapia e metade dos docentes dos cursos de Biomedicina e Educação Física.

A participação dos professores na nossa pesquisa forneceu dados importantes sobre como o docente universitário percebe as metodologias ativas e a necessidade de possuir competências pedagógicas para o desenvolvimento de tais metodologias.

\section{Resultados e discussões}

A nossa pesquisa com professores de cursos da área da saúde, de uma universidade mineira, mostrou como é importante a formação pedagógica do docente universitário para o desenvolvimento de práticas que acentuem a autonomia dos alunos, como as metodologias ativas. Mostrou também que tais práticas criam um tipo de aula que gera fatos positivos e agregadores tanto para docentes como para discentes.

Uma das questões, aberta, colocada aos professores, no questionário, é sobre a relação entre fatos importantes e positivos que ocorreram em sala de aula e a sua formação e prática docente. As respostas dos professores nos conduziram ao seguinte levantamento:

a) $20 \%$ dos professores respondentes relacionaram fatos importantes e positivos ocorridos no dia a dia da sala de aula como resultado da sua competência e formação pedagógica;

b) $20 \%$ dos professores relacionaram fatos importantes e positivos ocorridos em sala de aula como resultados do uso de metodologias que promovem a participação e a aprendizagem ativa.

c) $4 \%$ dos professores participantes relacionaram fatos importantes e positivos do cotidiano docente como resultado de esforços conjuntos dos professores e alunos.

Diversos professores ${ }^{7}$ relacionaramas aulas mais produtivas e positivas com aquelas em houve uma maior participação e autonomia dos alunos, conforme os comentários a seguir:

${ }^{7}$ Os professores, para preservar o anonimato, estão representados pela letra “ $D$ ”, seguida de um algarismo arábico. 
“A participação do aluno com seu olhar virgem sobre os assuntos das disciplinas traz novas interpretações que, muitas vezes, tenho que pesquisar para dar resposta em uma próxima aula. Isto estimula a busca do saber por parte do professor e do aluno." D2

"Incentivo...desenvolvimento da capacidade crítica e reflexiva... que os alunos tenham uma participação ativa nos debates e os conhecimentos adquiridos da própria prática acadêmica.” D9

"Incentivo ao diálogo e o feedback por parte dos alunos." D15

"O desafio lançado aos alunos é que os faz aprimorarem a si mesmos.” D11

Algo interessante que percebemos nos comentários dos docentes acima é o valor que atribuem à participação ativa dos alunos como um ingrediente importante para uma boa aula. No entanto, notamos, nas suas declarações, a ausência de conhecimentos de métodos específicos para fomentar esse tipo de participação. Certamente, essa omissão das metodologias ativas se deve à lacuna na formação pedagógica desses docentes universitários, o que foi constatado por outros pesquisadores da área (MASETTO, 2003a; VASCONCELOS, 2000). Ainda assim, a sua atitude intuitiva de estimular a autonomia dos alunos, por meio do diálogo, da participação, da pesquisa autodirigida e de desafios propostos, é muito relevante.

Essa necessidade formativa pode ser constatada nos comentários a seguir:

"Atribuo como fatores de extrema relevância em minha prática docente a formação continuada e o desenvolvimento de habilidades sociais e educativas que irão garantir o adequado relacionamento com os alunos no espaço universitário, quer em sala de aula, quer na realização de pesquisas ou mesmo em espaços comuns do campus”. D4.

Verificamos, na declaração acima, que o professor reconhece a necessidade de uma formação continuada que propicie o desenvolvimento de habilidades sociais e educativas. Isso acontece porque boa parte dos professores universitários tem formação no bacharelado e um ou mais tipos de pós-graduação que não "contemplam de modo geral a formação pedagógica”, segundo Gil (2007, p.20). Por isso, um dos professores pesquisados atribuiu os bons resultados que tem alcançado na sua prática docente a uma formação pedagógica complementar, conforme as suas palavras:

“... uma passagem pelos ensinamentos da didática e da metodologia científica que fortaleceram o meu 
caminhar pelo ensino e pesquisa." D5

Ainda assim, observamos que ainda prevalece uma cultura, entre os professores investigados, de que basta a pesquisa e a atualização dentro da sua área específica de conhecimento científico. Um exemplo dessa forma de pensar, constatada por Masetto (2003a; 2003b), pode ser notado na seguinte resposta de um professor:

"Nunca ocorreu nada de muito extraordinário. O melhor é o fato de que, ao ensinar, estou sempre aprendendo e me desenvolvendo, o que eu atribuo ao fato de procurar sempre estudar os assuntos que leciono." D13

Naturalmente, é importante que o professor estude e se atualize quanto aos assuntos que leciona. Mas, como docente, como alguém que é um profissional do ensino, o professor universitário também necessita de uma formação pedagógica, que acrescente conhecimentos de técnicas e de métodos de ensino eficazes, como, por exemplo, as metodologias ativas. Nesse sentido, Gil (2007, p.27), ao tratar do professor universitário eficaz, argumenta que este precisa apresentar "eficácia instrucional”, ou seja, um conjunto de habilidades e destrezas “que conduzam ao aprendizado mesmo os estudantes mais relutantes”. Não queremos, com isso, fazer uma apologia a uma visão tecnicista do Ensino Superior, por reconhecermos o caráter humano, político e crítico do trabalho docente, mas mostrar que a formação pedagógica, por competências, conforme Masetto (2003a), é insdipensável para que o docente universitário atinja o objetivo do seu trabalho, a saber, a aprendizagem dos seus alunos.

\section{Conclusão}

As metodologias ativas de ensino-aprendizagem entraram no cenário universitário para ficar. Elas envolvem estratégias que colocam o aluno como protagonista do seu próprio processo de aprendizagem, tornando-o responsável por esse processo. Essas metodologias, que inovam na educação superior, são importantes no sentido de evocar ao caráter crítico e reflexivo, próprio do ensino universitário, elevando, portanto, o seu nível de aprendizagem.

Nesse cenário em mudança, é esperado do professor universitário que vista uma nova roupagem e um novo papel com um significado maior, indo além de mero transmissor de conteúdos para alguém que possui competência pedagógica, capaz de dominar não apenas um campo do saber científico, mas também de dominar conhecimentos e habilidades em torno do 
processo de ensino-aprendizagem, do currículo, das relações professor-aluno e aluno-aluno e das tecnologias educacionais.

Dentro dessa ótica, a nossa pesquisa com professores universitários da área da saúde, mostrou que as práticas docentes que proporcionam mais diálogo, autonomia e desafios aos alunos tornam as aulas mais ricas e memoráveis, dando novo sentido à docência universitária.

E com esses fundamentos é que defendemos a ampliação dessa linha de ação educativa, entendendo necessário um maior investimento na formação específica e pedagógica do docente, inclusive pela introdução das metodologias ativas como aspecto essencial da formação inicial e continuada de docentes do Ensino Superior.

Não é nenhuma novidade o discurso sobre a necessidade de uma nova política pública para a educação superior, pautada no planejamento e na atualização, visando à implantação de propostas inovadoras para a formação de professores em todos os níveis de ensino e em todas as áreas do conhecimento, como forma de superar a barreira que se ergue entre os alunos e professores por conta da vivência em mundos diferentes.

Justamente por isso entendemos válido todo o incentivo à introdução e a aplicação das metodologias ativas no Ensino Superior, principalmente como uma diretriz privilegiada, orientadora da ação educativa, inserida no contexto de uma política pública voltada para a superação da metodologia tradicional traduzida no currículo composto na linha: disciplinas propedêuticas - disciplinas profissionalizantes - disciplinas práticas.

Por fim, cabe ressaltar a fundamental importância da formação continuada do professor por meio de um espaço institucional aberto ao diálogo, que ofereça ao docente do Ensino Superior a oportunidade de refazer o percurso de aprendizagem que eventualmente não lhe foi permitido em sua formação, garantindo institucionalmente para esse docente um espaço de construção de novos saberes e competências e de atualização permanente.

\section{Referências}

ANDERSON, L. W. et al. A taxonomy for learning, teaching, and assessing: a revision of Bloom's taxonomy of educational objectives. New York: Longman, 2001. ISBN 0-80131903-X.

BARBOSA, E. F.; MOURA, D. G. Metodologias ativas de aprendizagem na educação profissional e tecnológica. B. Tec. Senac, Rio de Janeiro, v. 39, n.2, p. 48-67, maio/ago. 2013. Disponível em: <http://www.senac.br/media/42471/ os_boletim_web_4.pdf>. Acesso em: 16 abr. 2016. ISSN 2448-1483.

BERGER, P. L.; LUCKMANN, T. A construção social da realidade: tratado de sociologia do conhecimento. 24. ed. Trad. Floriano S. Fernandes. Petrópolis: Vozes, 2004.ISBN 85-3249588-2. 
BRASIL. Lei no 9.394, de 20 de dezembro de 1996. Diário Oficial da União, Brasília, DF, 23 dez. 1996.

FREIRE, P. Pedagogia do oprimido. 54. ed. Rio de Janeiro: Paz e Terra, 2013. ISBN 978-857753-164-6.

GEMIGNANI, E. Y. M. Y.. Formação de professores e Metodologias Ativas de EnsinoAprendizagem: Ensinar para a compreensão. Revista Fronteiras da Educação: RecifePE,v.1,n.2,2012.Disponívelem:

<http://www.fronteirasdaeducacao.org/index.php/fronteiras/article/view/14>. Acesso em: 28 mai. 2016 00:25.ISSN: 2237-9703.

GIL, A. C. Didática do ensino superior. São Paulo: Atlas, 2007. ISBN 978-85-224-4392-5.

MALUSÁ, S. Investigação sobre a atualização docente no ensino superior. In: MALUSÁ, S.; FELTRAN, R. C. S. (org.). A prática da docência universitária. São Paulo: Factash Editora, 2003. ISBN 85-89909-05-0.

MASETTO, M. T. Competência pedagógica do professor universitário. São Paulo: Summus, 2003a. ISBN 978-85-323-0831-3.

Professor universitário: um profissional da educação na atividade

docente. In: Docência na universidade. 6.ed. Campinas, SP: Papirus, 2003b.

ISBN 85-308-0509-7.

Docência universitária: repensando a aula. In: TEODORO, A.; VASCONCELOS, M. L. (org.). Ensinar e aprender no ensino superior: por uma epistemologia da curiosidade na formação universitária. 3.ed. São Paulo: Universidade Presbiteriana Mackenzie; Cortez, 2012. ISBN 978-85-249-1995-4.

MAZUR, E. Peer instruction: a revolução da aprendizagem ativa. Trad. Anatólio Laschuk. Porto Alegre: Penso, 2015. ISBN 978-85-8429-062-8.

MOTA, R.; SCOTT, D. Educando para a inovação e aprendizagem independente. Rio de Janeiro: Elsevier, 2014. ISBN 978-85-352-7039-6.

REY, F. L. G. La subjetividad social y su expresión en la enseñanza. Temas em Psicologia, n.3, p. 95-107, 1997. ISSN 1413-389X.

VASCONCELOS, M. L. M. C. Contribuindo para a formação de professores universitários: relato de experiências. In: MASETTO, M. T. Docência na universidade. 6.ed. Campinas, SP: Papirus, 2003b. ISBN 85-308-0509-7.

ZABALZA, M. O ensino universitário: seu cenário e seus protagonistas. Trad. Ernani Rosa. Por to Alegre: Artmed, 2004. ISBN 978-85-363-02 14-0. 